\title{
Public Education Expenditure, Growth and Welfare*
}

\author{
Konstantinos Angelopoulos \\ University of Stirling \\ Jim Malley \\ University of Glasgow and CESifo \\ Apostolis Philippopoulos \\ Athens University of Economics \& Business and CESifo
}

June 5, 2007

\begin{abstract}
In this paper we study the quantitative macroeconomic effects of public education spending in USA for the post-war period. Using comparable measures of human and physical capital, from Jorgenson and Fraumeni $(1989,1992 a, b)$, we calibrate a standard dynamic general equilibrium model where human capital is the engine of long-run endogenous growth and government education spending is justified by externalities in human capital. Our base calibration, based on moderate sized human capital externalities, suggests that public spending on education is both growth and welfare promoting. However, given that pubic education spending crowds-out private consumption, the welfare maximising size of the government is less than the growth maximising one. Our results further suggest that welfare gains, as high as four percent of consumption, are obtainable if the composition of public spending can be altered in favour of education spending relative to the other components of total government spending.
\end{abstract}

${ }^{*}$ We would like to thank Fabrice Collard, Harris Dellas, Campbell Leith, Ioana Moldovan, Michael Moore, Jonathan Temple, Klaus Wälde, Ulrich Woitek and seminar participants at the Queens University Belfast for helpful suggestions. The usual disclaimer applies. 
"If ideas are the engine of growth and if an excess of social over private returns in an essential feature of the production of ideas, then we want to go out of our way to introduce external effects into growth theory, not to try to do without them". [Lucas 2002]

\section{Introduction}

The path-breaking work of Romer (1986) and Lucas (1988), stressing the roles of knowledge and human capital accumulation, has led to an enormous body of theoretical ${ }^{1}$ and empirical ${ }^{2}$ literature attempting to better understand the determinants of endogenous growth. The same literatures have also emphasized the central role played by externalities associated with human capital accumulation. ${ }^{3}$ The importance of externalities in this context is highlighted by Lucas (2002), who states that "the existence of important external effects of investment in human capital - in knowledge - has long been viewed as an evident and important aspect of reality".

Despite the obvious need, from a policy perspective, to understand the quantitative links between externalities, human capital accumulation and growth, there has been surprisingly little empirical work at the aggregate level. Indeed, we are only aware of one study which attempts to directly estimate human capital externalities in a growth context (see Gong, Greiner and Semmler (2004)) and several others which examine the link between externalities and the level of aggregate output (see, e.g. Mamuneas et al. (2001) and Heckman and Klenow (1997)). ${ }^{4}$

In the presence of human capital externalities, a clear case for fiscal policy intervention can be made and in particular a role for government education

\footnotetext{
${ }^{1}$ See, e.g. Barro and Sala-i-Martin (2004) and Aghion and Howitt (1999) for references as well as Romer (1990) for an excellent review paper.

${ }^{2}$ Empirical studies on the role of human capital based on reduced-form cross-sectional country or panel regressions, unequivocally find a significant link between average years of schooling and growth (see, e.g. Barro and Sala-i-Martin (2004), Barro (2001, 1991), de la Fuente and Domenech (2001)). Another set of studies estimates the steady-state relationship between growth and human capital implied by the solution of extended Solow or Lucas-type models also concludes that human capital contributes either directly or indirectly (via total factor productivity) to growth, see, e.g. Mankiw, Romer and Weil (1992), Benhabib and Spiegel (1994), Bils and Klenow, 2000 and Temple (2001).

${ }^{3}$ Klenow and Rodrigues-Clare (2005) provide a very good review of these studies and include discussion of externalities associated with the accumulation of human capital, organizational capital, the introduction of new goods, or some combination of these.

${ }^{4}$ There has however been much more work at the sub-aggregate level (see the review paper by Davies (2003) for references).
} 
policy. Despite rich and growing theoretical ${ }^{5}$ and empirical ${ }^{6}$ literatures on the relationship between fiscal policy and economic growth, we are again not aware of any estimation or calibration research which explores the empirical links between education spending policy, human capital externalities and growth.

Given the potential benefits from policy and the lack of quantitative research to date, in this paper we calibrate, solve and conduct policy analysis using a standard endogenous growth model. In the spirit of Lucas's (2002) observations stated above, the model's engine of long-term growth is human capital accumulation in the presence of externalities. More specifically, following Tamura (1991) we specify a model which allows for positive externalities associated with the stock of aggregate human capital. This externality in turn justifies the provision of public education which acts to directly affect the accumulation of embodied human capital.

Our calibration profits significantly from having access to a dataset which includes consistent measures for human and physical capital (see, e.g. Jorgenson and Fraumeni (1989)). In contrast to the relevant empirical studies referred to above, this data allows us to correctly distinguish between inputs to and output from the human capital production function. ${ }^{7}$ Accordingly, while no consensus has yet emerged on the precise quantitative role of externalities from the empirical micro and macro studies, our contribution is to examine the effects of a range of externalities on aggregate growth and welfare based on a careful calibration using a unique dataset.

To be in a position to realistically assess the effects of public education spending on growth, we assume that this spending is financed by a distortionary tax on income. Hence, the growth effects of this spending will not be monotonic. We then use the calibrated model to shed light on the critical issues pertaining to the sign and magnitude of fiscal policy on long-run growth, lifetime welfare as well as the cyclical path of the economy along the transition path.

Our main findings are as follows. First, based on moderate sized human

\footnotetext{
${ }^{5}$ One of the most popular models is Barro (1990) in which government productive expenditure, financed by distorting tax rates, is the engine of long-term growth. There are numerous extensions of this model in the literature (see e.g., Malley et al. (2007), Barro and Sala-i-Martin, (2004) ch. 4, Park and Philippopoulos, (2004, 2003), Baier and Glomm (2001), Glomm and Ravikumar, (1994, 1997), and Turnovsky and Fischer (1995).

${ }^{6}$ The empirical evidence on the relationship between fiscal policy and growth is vast and the results so far have been mixed (see e.g., Mueller (2003, ch. 22), Gemmel and Kneller (2001) and Tanzi and Zee (1997), for surveys of this literature).

${ }^{7}$ Given the lack of comparable cross-country human capital data, other empirical work generally resorts to the use of measures of school enrolment ratios or years of schooling as general proxies of labor quality or human capital.
} 
capital externalities, our results suggests that public spending on education is both growth and welfare promoting. However, given that pubic education spending crowds-out private consumption, the welfare maximising size of the government is less than the growth maximising one. Second, we find that substantial welfare gains are obtainable if the composition of public spending can be altered in favour of education spending relative to the other components of total government spending. These welfare gains, calculated using the solution to the second-order approximation of the model, amount to 4percent of consumption and correspond to an education spending share of 8.5\%. Third, the positive welfare effects of education spending work through human capital externalities. In particular, in the presence of higher externalities, the model predicts that the welfare maximizing education spending is higher. Intuitively, a larger gap between private and social returns under higher externalities makes government intervention more beneficial. Finally, we find that a positive education spending shock generates a non-monotonic reaction in the growth rate and other key economic variables, so that after an initial boom there is a decrease in the growth rate below its steady-state value. The quantitative effects of discretionary fiscal policy of this form are not trivial as they are similar in magnitude to those of a standard TFP shock.

The rest of the paper is organized as follows. Section 2 summarizes the theoretical model. Section 3 discusses the data and calibration. Section 4 contains the results and Section 5 the conclusions. Finally, the Appendices present further information on the steady-state, the second-order welfare function and second-order impulse response functions.

\section{The Theoretical Model}

In this section, building on Lucas's (1990) model of human capital, we solve for the optimal decisions of households and firms when the engine of longterm growth is human capital accumulation in the presence of aggregate externalities. We choose this model because it is well known and its conclusions are rather robust (see, e.g. Stokey and Rebelo (1995) for a quantitative comparison of some important DSGE models of human capital).

To conduct our analysis, we add several elements to the Lucas (1990) setup. These include the two main types of productive government spending (i.e. government expenditure on infrastructure and public education) and the externalities generated by the per capita human capital stock of the society. The role of the latter has been emphasized by amongst others Lucas (1988) and Tamura (1991) and can justify the provision of public education spending in the model. In our setup, government infrastructure acts as a public good 
that enhances the productivity of private firms when they produce output, while public education acts as a public good that enhances the productivity of households' private education choices.

The general equilibrium solution of the model consists of a system of dynamic relations jointly specifying the paths of output, consumption, private and public physical capital, human capital growth and the fractions of time allocated to work and education. To obtain these paths we solve the second-order approximation of our model's equilibrium conditions around the deterministic steady-state (see, e.g. Schmitt-Grohé and Uribe (2004)). In contrast to solutions which impose certainty equivalence, the solution of the second-order system allows us to take account of the uncertainty agents face when making decisions. As pointed out by e.g. Schmitt-Grohé and Uribe (2004) and Kim and Kim (2003), the second-order approximation to the model's policy function helps to avoid potential spurious welfare rankings which may arise under certainty equivalence.

\subsection{Households}

The model is populated by a large number of identical households indexed by the subscript $h$ and identical firms indexed by the subscript $f$, where $h, f=1,2, \ldots, N_{t}$. The population size, $N_{t}$, evolves at a constant rate $n \geq 1$, so that $N_{t+1}=n N_{t}$, where $N_{0}$ is given. Each household's preferences are given by the following time-separable utility function:

$$
E_{0} \sum_{t=0}^{\infty} \beta^{t} U\left(C_{t}^{h}\right)
$$

where $E_{0}$ is the conditional expectations operator; $C_{t}^{h}$ is consumption of household $h$ at time $t$; and $0<\beta<1$ is the subjective rate of time preference. The instantaneous utility function is increasing, concave and satisfies the Inada conditions. We use the $C R R A$ form for utility:

$$
U_{t}=\frac{\left(C_{t}^{h}\right)^{1-\sigma}}{1-\sigma}
$$

where, $1 / \sigma(\sigma>1)$ is the intertemporal elasticity of substitution between consumption in adjacent periods.

Each household saves in the form of investment, $I_{t}^{p, h}$ and receives interest income, $r_{t} K_{t}^{p, h}$, where $r_{t}$ is the return to private capital and $K_{t}^{p, h}$ (the $p$ superscript refers to private agents) is the beginning-of-period private capital stock. Each household also has one unit of time endowment in each period 
$t$, which it allocates to work, $u_{t}^{h}$ and education, $e_{t}^{h}$, so that $u_{t}^{h}+e_{t}^{h}=1^{8}$. A household with a stock of human capital, $H_{t}^{h}$ receives labour income, $w_{t} u_{t}^{h} H_{t}^{h}$, where $w_{t}$ is the wage rate and $u_{t}^{h} H_{t}^{h}$ is effective labour. Finally, each household receives dividends paid by firms, $\Pi_{t}^{h}$. Accordingly, the budget constraint of each household is

$$
C_{t}^{h}+I_{t}^{p, h}=\left(1-\tau_{t}\right)\left[r_{t} K_{t}^{p, h}+w_{t} u_{t}^{h} H_{t}^{h}+\Pi_{t}^{h}\right]+\bar{G}_{t}^{o}
$$

where $0<\tau_{t}<1$ is the distortionary income tax rate and $\bar{G}_{t}^{o}$ is an average (per household) lump-sum tax/subsidy. ${ }^{9}$

Each household's physical and human evolve according to the following relations

$$
K_{t+1}^{p, h}=I_{t}^{p, h}+\left(1-\delta^{p}\right) K_{t}^{p, h}
$$

and

$$
H_{t+1}^{h}=\left(1-\delta^{h}\right) H_{t}^{h}+\left(e_{t}^{h} H_{t}^{h}\right)^{\theta_{1}}\left(\bar{H}_{t}\right)^{1-\theta_{1}} \widetilde{B}_{t}
$$

where, $0 \leq \delta^{p}, \delta^{h} \leq 1$ are constant depreciation rates on private physical and human capital respectively. The second expression on the r.h.s. of (5), consisting of three multiplicative terms, can be interpreted as the quantity of "new" human capital created at time period $t$. This expression is comprised of the following arguments: (i) $\left(e_{t}^{h} H_{t}^{h}\right)$ is $h^{\prime} s$ effective human capital; (ii) $\bar{H}_{t}$ is the average (per household) human capital stock in the economy; (iii) $\widetilde{B}_{t} \equiv$ $B\left(g_{t}^{e}\right)^{\theta_{2}}$ represents human capital productivity, where $B>0$ is a constant scale parameter and $g_{t}^{e}$ is average (per household) public education expressed in efficiency units (see below); (iv) the parameters $0<\theta_{1},\left(1-\theta_{1}\right), \theta_{2}<1$ capture the productivity of household human capital, the aggregate human capital externality and public education spending respectively.

The assumption that individual human capital accumulation is an increasing function of the per capita level of economy-wide human capital encapsulates the idea that the existing know-how of the economy provides an external positive effect. Equivalently it can be thought of as a learningby-doing effect as discussed in Romer (1986). Examples of other papers which use the per capita level of aggregate human capital in either the goods or human capital production functions include Lucas (1988), Azariadis and Drazen, (1990) and Tamura (1991). Also note that the role played by the

\footnotetext{
${ }^{8}$ Following the human capital literature, which includes education as a choice variable, we do not endogenize leisure choice since this generally leads to multiple long-run equilibria (see e.g. Ortigueira, 1998, who also provides relevant references). Stokey and Rebelo (1995) also discuss the implications of elastic labour supply in growth models with human capital.

${ }^{9}$ The role played by $\bar{G}_{t}^{o}$ will be explained below in subsection 2.3 .
} 
per household public education share, $g_{t}^{e}$, in (5) is consistent with the goal of public education policy as well as theoretical work (see e.g. Glomm and Ravikumar (1992), Blankenau and Simpson (2004), Su (2004) and Blankenau (2005)). ${ }^{10}$ Finally note that, the parameter restrictions employed in (5) imply increasing returns to scale (IRS) at the social level. ${ }^{11}$

Households act competitively by taking prices, policy variables and aggregate outcomes as given. Thus, each household chooses $\left\{C_{t}^{h}, u_{t}^{h}, e_{t}^{h}, I_{t}^{p, h}, K_{t+1}^{p, h}\right.$, $\left.H_{t+1}^{h}\right\}_{t=0}^{\infty}$ to maximize (1) subject to (3), (4), (5), the time constraint $u_{t}^{h}+e_{t}^{h}=$ 1 , and initial conditions for $K_{0}^{p, h}$ and $H_{0}^{h}$.

Substituting (4) into (3) for $I_{t}^{p, h}$ and using the time constraint for $u_{t}^{h}$, we next derive the first order conditions. The familiar static optimality condition for consumption, $C_{t}^{h}$, is

$$
\Lambda_{t}^{h}=\left(C_{t}^{h}\right)^{-\sigma}
$$

and states that the shadow price associated with $(3), \Lambda_{t}^{h}$, is equal to the marginal value of consumption at time $t$.

The Euler-relation for private physical capital, $K_{t+1}^{p, h}$, is given by

$$
\Lambda_{t}^{h}=\beta E_{t} \Lambda_{t+1}^{h}\left[1-\delta^{p}+\left(1-\tau_{t+1}\right) r_{t+1}\right]
$$

and reveals that the marginal cost of forgone consumption at time $t$ is equal to the expected marginal benefit of discounted $t+1$ net (of tax) returns derived from investing in one unit of physical capital at time $t$.

The static optimality condition for time spent on education, $e_{t}^{h}$, can be written as

$$
\Psi_{t}^{h}=\frac{\Lambda_{t}^{h}\left(1-\tau_{t}\right) w_{t} H_{t}^{h}}{B \theta_{1}\left(e_{t}^{h}\right)^{\theta_{1}-1}\left(H_{t}^{h}\right)^{\theta_{1}}\left(\bar{H}_{t}\right)^{1-\theta_{1}}\left(g_{t}^{e}\right)^{\theta_{2}}}
$$

and says that the shadow price associated with (5), $\Psi_{t}^{h}$, is equal to the marginal value of education at time $t$.

The Euler-equation for private human capital, $H_{t+1}^{h}$, is

$$
\begin{aligned}
\Psi_{t}^{h}= & \beta E_{t} \Lambda_{t+1}^{h}\left(1-\tau_{t+1}\right) w_{t+1} u_{t+1}^{h}+ \\
& \beta E_{t} \Psi_{t+1}^{h}\left[\left[1-\delta^{h}+B \theta_{1}\left(e_{t+1}^{h}\right)^{\theta_{1}}\left(H_{t+1}^{h}\right)^{\theta_{1}-1}\left(\bar{H}_{t+1}\right)^{1-\theta_{1}}\left(g_{t+1}^{e}\right)^{\theta_{2}}\right]\right.
\end{aligned}
$$

\footnotetext{
${ }^{10}$ Blankenau (2005, pp. 493-4) also has a good discussion of the effects of public education on students' achievement.

${ }^{11}$ Lucas (1988) and Benhabib and Perli (1994) are examples of other studies which employ the IRS assumption in either or both the physical and human capital production functions.
} 
and expresses that the marginal cost of forgone labour income at time $t$ is equal to the marginal benefit of discounted net (of tax) $t+1$ returns to working plus the marginal $t+1$ returns to investing in one unit of human capital at time $t$.

Finally, the transversality conditions

$$
\lim _{t \rightarrow \infty}\left[\beta^{t} U_{C^{h}}(t) K_{t+1}^{h}\right]=0
$$

and

$$
\lim _{t \rightarrow \infty}\left[\beta^{t} U_{C^{h}}(t) H_{t+1}^{h}\right]=0
$$

maintain and state that the discounted value of a household's physical and human assets must approach zero in the limit. Otherwise, utility could be increased by higher consumption.

\section{$2.2 \quad$ Firms}

To produce its homogenous final product, $Y_{t}^{f}$, each firm, $f$, chooses private physical capital, $K_{t}^{p, f}$, and effective labour, $u_{t}^{f} H_{t}^{f}$, and takes advantage of average (per firm) public infrastructure as a share of average (per firm) human capital, $k_{t}^{g}$, expressed in efficiency units (see below) Thus, the production function of each firm is:

$$
Y_{t}^{f}=\widetilde{A}_{t}\left(K_{t}^{p, f}\right)^{\alpha_{1}}\left(u_{t}^{f} H_{t}^{f}\right)^{1-\alpha_{1}}
$$

where $\widetilde{A}_{t} \equiv A_{t}\left(k_{t}^{g}\right)^{\alpha_{2}} ; A_{t}$ represents the level of Hick neutral neutral technology available to all firms, $0<\alpha_{1},\left(1-\alpha_{1}\right), \alpha_{2}<1$ are the productivity of private capital and labour and public capital respectively. Following, e.g. Baxter and King (1993), the parameter restrictions employed in (12) imply increasing returns to scale (IRS) at the social level.

Firms act competitively by taking prices, policy variables and aggregate outcomes as given. Accordingly, subject to (12), each firm chooses $K_{t}^{p, f}$ and $u_{t}^{f} H_{t}^{f}$ to maximize a series of static profit functions,

$$
\Pi_{t}^{f}=Y_{t}^{f}-r_{t} K_{t}^{p, f}-w_{t} u_{t}^{f} H_{t}^{f} .
$$

The resulting familiar first-order conditions state that the firm will hire labour until the marginal product of effective labour is equal to the wage rate, $w_{t}$, and will rent capital until the marginal product of physical capital is equal to the rental rate, $r_{t}$, i.e.

$$
\frac{\left(1-\alpha_{1}\right) Y_{t}^{f}}{u_{t}^{f} H_{t}^{f}}=w_{t}
$$




$$
\frac{\alpha_{1} Y_{t}^{f}}{K_{t}^{f}}=r_{t}
$$

\subsection{Government}

Total government investment, $G_{t}^{i}$, total expenditure on public education, $G_{t}^{e}$ and all other types of public spending, $G_{t}^{o}$, are financed by total tax revenue. Thus,

$$
G_{t}^{e}+G_{t}^{i}+G_{t}^{o}=\tau_{t} \sum_{h=1}^{N_{t}}\left(r_{t}^{k} K_{t}^{h}++w_{t} u_{t}^{h} H_{t}^{h}+\Pi_{t}^{h}\right)
$$

where only three of the four policy instruments can be exogenously set. ${ }^{12}$

When we solve the model, we will choose the tax rate to be the endogenous or residually determined policy instrument so that the effects of increases in government spending on education and infrastructure can be credibly assessed. The inclusion of $G_{t}^{o}$ will make the residually determined value of the tax rate correspond to the rate which exists in the data. This will allow for a realistic assessment of the trade-offs between increased spending on public goods versus increased distortions due to higher tax rates.

Finally, total government investment, $G_{t}^{i}$, is used to augment the stock of public capital whose motion is given by:

$$
K_{t+1}^{g}=G_{t}^{i}+\left(1-\delta^{g}\right) K_{t}^{g}
$$

where $0 \leq \delta^{g} \leq 1$ is a constant depreciation rate on public physical capital.

\subsection{Stationary decentralized competitive equilibrium}

Given the paths of the exogenously set policy instruments, $\left\{G_{t}^{e}, G_{t}^{i}, G_{t}^{o}\right\}_{t=0}^{\infty}$ and initial conditions for the state variables $\left(K_{0}^{p, h}, H_{0}^{h}, K_{0}^{g}\right)$, a decentralized competitive equilibrium $(D C E)$ is defined to be a sequence of allocations $\left\{C_{t}, u_{t}, e_{t}, I_{t}^{p}, K_{t+1}^{p}, H_{t+1}, K_{t+1}^{g}\right\}_{t=0}^{\infty}$, prices $\left\{r_{t}, w_{t}\right\}_{t=0}^{\infty}$ and the tax rate $\left\{\tau_{t}\right\}_{t=0}^{\infty}$ such that (i) households maximize utility; (ii) firms maximize profits; (iii) all markets clear; (iv) the government budget constraint as well as the motion of public capital are satisfied in each time period. Note that market clearing values will be denoted without the superscripts $h, f$.

Since human capital is the engine of long-run endogenous growth, we transform variables to make them stationary. Following the literature (see,

\footnotetext{
${ }^{12}$ In other words, we use a balanced budget without debt. Ignoring debt is not critical here since in this class of model, public finance variables do not affect the real allocation of the economy.
} 
e.g. Lucas 1990), we first define per capita quantities for any variable $X$ as $\bar{X}_{t} \equiv X_{t} / N_{t}$, where $X_{t} \equiv\left(Y_{t}, C_{t}, I_{t}^{p}, K_{t}^{p}, H_{t}, K_{t}^{g}, G_{t}^{i}, G_{t}^{e}, G_{t}^{o}\right)$. We next express these quantities as shares of per capita human capital, e.g. $x_{t} \equiv \bar{X}_{t} / \bar{H}_{t}$. Finally, the gross human capital growth rate is defined as $\gamma_{t} \equiv \bar{H}_{t+1} / \bar{H}_{t}$.

Using this notation, substituting out prices $\left\{r_{t}, w_{t}\right\}_{t=0}^{\infty}$ and substituting for $\Lambda_{t}$ and $\Lambda_{t+1}$ in (8) and (9) respectively, we obtain the following per capita stationary $D C E$ :

$$
\begin{gathered}
y_{t}=A_{t}\left(k_{t}^{p}\right)^{\alpha_{1}}\left(1-e_{t}\right)^{\left(1-\alpha_{1}\right)}\left(k_{t}^{g}\right)^{\alpha_{2}} \\
n \gamma_{t} k_{t+1}^{p}-\left(1-\delta^{p}\right) k_{t}^{p}+c_{t}+g_{t}^{i}+g_{t}^{e}=y_{t} \\
n \gamma_{t}=1-\delta^{h}+\left(e_{t}\right)^{\theta_{1}} B\left(g_{t}^{e}\right)^{\theta_{2}} \\
n \gamma_{t} k_{t+1}^{g}=\left(1-\delta^{g}\right) k_{t}^{g}+g_{t}^{i} \\
\lambda_{t}=\left(c_{t}\right)^{-\sigma} \\
\lambda_{t}=\beta\left(\gamma_{t}\right)^{-\sigma} E_{t}\left\{\lambda_{t+1}\left[1-\delta^{p}+\frac{\alpha_{1}\left(1-\tau_{t+1}\right) y_{t+1}}{k_{t+1}^{p}}\right]\right\} \\
\psi_{t}=\left[\frac{\left(c_{t}\right)^{-\sigma}\left(1-\alpha_{1}\right)\left(1-\tau_{t}\right) y_{t}}{\left(1-e_{t}\right) \theta_{1}\left(e_{t}\right)^{\theta_{1}-1} B\left(g_{t}^{e}\right)^{\theta_{2}}}\right] \\
\psi_{t}=E_{t}\left\{\left(\gamma_{t} c_{t+1}\right)^{-\sigma}\left(1-\alpha_{1}\right)\left(1-\tau_{t+1}\right) y_{t+1}+\beta\left(\gamma_{t}\right)^{-\sigma} \times\right. \\
\left.\psi_{t+1}\left[1-\delta^{h}+\theta_{1}\left(e_{t+1}\right)^{\theta_{1}} B\left(g_{t+1}^{e}\right)^{\theta_{2}}\right]\right\} \\
g_{t}^{i}+g_{t}^{e}+g_{t}^{o}=\tau_{t} y_{t}
\end{gathered}
$$

where $\lambda_{t}$ and $\psi_{t}$ are the transformed shadow prices associated with (3) and (5) respectively in the household's problem. ${ }^{13}$

Therefore, the stationary DCE is summarized by the above system of nine equations in the paths of the following nine variables: $\left(\gamma_{t}, y_{t}, c_{t}, e_{t}, k_{t+1}^{p}, k_{t+1}^{g}\right.$, $\left.\lambda_{t}, \psi_{t}, \tau_{t}\right)$ given the paths of the exogenously set stationary spending flows, $\left\{g_{t}^{i}, g_{t}^{e}, g_{t}^{o}\right\}_{t=0}^{\infty}$ whose motion is defined below.

\footnotetext{
${ }^{13}$ Note that $\lambda_{t}=\Lambda_{t} / \bar{H}_{t}^{-\sigma}$ and $\psi_{t}=\Psi_{t} / \bar{H}_{t}^{-\sigma}$ where $h$-superscripts are omitted in a symmetric equilibrium.
} 


\subsection{Processes for the fiscal instruments and technology}

We next specify the processes governing the evolution of public spending items as shares of output. This first requires that each spending instrument, which has already been expressed as share of $\bar{H}_{t}$, be rewritten equivalently as:

$$
g_{t}^{j} \equiv \widetilde{g}_{t}^{j} y_{t}
$$

where $[j=e, i, o]$, and $\widetilde{g}_{t}^{j} \equiv G_{t}^{j} / Y_{t}$.

We then specify processes for each of the three instrument rates in (19) as follows

$$
\begin{gathered}
\widetilde{g}_{t}^{i}=\left(\frac{g^{i}}{g}\right) \widetilde{g}_{t} \\
\widetilde{g}_{t}^{o}=\left(\frac{g^{o}}{g}\right) \widetilde{g}_{t} \\
\widetilde{g}_{t}^{e}=\left(\widetilde{g}^{e}\right)^{1-\rho^{e}}\left(\widetilde{g}_{t-1}^{e}\right)^{\rho^{e}} e^{\varepsilon_{t}^{e}}
\end{gathered}
$$

where $g \equiv g^{e}+g^{i}+g^{o} ; \widetilde{g}_{t} \equiv \widetilde{g}_{t}^{e}+\widetilde{g}_{t}^{i}+\widetilde{g}_{t}^{o} ; 0<\rho^{e}<1$ is the autoregressive parameter and $\varepsilon_{t}^{e}$ an iid random shock to public education with a zero mean and constant standard deviation, $\sigma_{e}$.

In order to assess the effects of public education spending, we specify an $\operatorname{AR}(1)$ process in (22) where the innovations $\varepsilon_{t}^{e}$ represent discretionary education spending changes. Consistent with the US data, the policy rules (20) and (21) imply that the government investment and other government spending as shares of output are constant fractions of total government spending as a share of output, where the fractions are given by the means of $\left(\frac{g^{i}}{g}\right)$ and $\left(\frac{g^{o}}{g}\right)$ in the data. In this state (called policy regime A) the composition of public expenditure remains constant when the government spending as a share of output changes. We will also examine the policy scenario where the government investment and other government spending as shares of output do not react to changes in government education spending. In this case they are instead fixed at a specific share which can be obtained by setting $\widetilde{g}_{t}=g$ in policy rules (20) and (21)). In this state (called policy regime B), the composition of government spending changes when $\widetilde{g}_{t}^{e}$ changes, but the shares of government investment and other government spending spending over output remain constant.

Finally the stationary stochastic process determining $A_{t}$ is an exponential first-order Markov process

$$
A_{t}=A^{\left(1-\rho^{a}\right)} A_{t-1}^{\rho^{a}} e^{\varepsilon_{t}^{a}}
$$


where $A>0$ is a constant, $0<\rho^{a}<1$ is the autoregressive parameter and $\varepsilon_{t}^{a} \sim \operatorname{iid}\left(0, \sigma_{a}^{2}\right)$ are the random shocks to productivity.

\section{Data and Calibration}

\subsection{Data}

To calibrate the model, we first require data for the endogenous variables as shares of human capital. Thus it is important to obtain a measure of human capital that is comparable to monetary valued quantities such as consumption, income, public and private capital and government spending. To obtain this, we use data from Jorgenson and Fraumeni (1989, 1992a,b) on human and physical capital. ${ }^{14}$ These measures are reported in billions of constant 1982 dollars for 1949-1984.

The basic idea used in the construction of this dataset is that the output of the education sector is considered as investment in human capital. In this context, Jorgenson and Fraumeni (1992a) note: "investment in human beings, like investment in tangible form of capital such as buildings and industrial equipment, generates a stream of future benefits. Education is regarded as an investment in human capital, since benefits accrue to an educated individual over a lifetime of activities". Jorgenson and Fraumeni (1989) also note that "in order to construct comparable measures of investment in human and nonhuman capital, we define human capital in terms of lifetime labor incomes for all individuals in the US population. Lifetime labor incomes correspond to asset values for investment goods used in accounting for physical or nonhuman capital".

The additional (annual) data required for calibration are obtained from the following sources: (i) Bureau of Economic Analysis (NIPA accounts); (ii) OECD (Economic Outlook database); (iii) US Department of Labor, Bureau of Labor Statistics (BLS); and (iv) ECFIN Effective Average Tax Base (see Martinez-Mongay, 2000).

\footnotetext{
${ }^{14}$ Generally empirical studies use measures of school enrolment ratios or years of schooling as general proxies of labor quality or human capital. However, in our setup, these proxies are measures of the input to the production function of human capital (time spent on education) and not of the output of this activity, new human capital.
} 


\subsection{Calibration}

The numeric values for the model's parameters are reported in Table 1. To calibrate the model, we work as follows. ${ }^{15}$ We set the value of $\left(1-\alpha_{1}\right)$ equal to labor's share in income (i.e. 0.578) using compensation of employees data from the OECD Economic Outlook. This figure is similar to others used in the literature, see e.g. King and Rebelo (1988) and Lansing (1998). Given labour's share, capital's share, $\alpha_{1}$, is then determined residually. Following e.g. Baxter and King (1993), the exponent of public infrastructure in the production function $\alpha_{2}$ is equal to the government investment share in GDP, i.e. 0.041, obtained from the NIPA accounts. ${ }^{16}$

\begin{tabular}{lrl}
\hline & Table 1: Parameter Values (base calibration) \\
\hline \hline parameter & value & definition \\
$A>0$ & 0.077 & technological progress in goods production \\
$B>0$ & 0.464 & technological progress in human capital production \\
$0<\alpha_{1}<1$ & 0.422 & productivity of private capital \\
$0<1-\alpha_{1}<1$ & 0.578 & productivity of effective labor \\
$0<\alpha_{2}<1$ & 0.041 & productivity of public capital \\
$0<\beta<1$ & 0.964 & rate of time preference \\
$n \geq 1$ & 1.016 & population growth \\
$0 \leq \delta^{p} \leq 1$ & 0.049 & depreciation rate on private capital \\
$0 \leq \delta^{h} \leq 1$ & 0.018 & depreciation rate on human capital \\
$0 \leq \delta^{g} \leq 1$ & 0.049 & depreciation rate on public capital \\
$0<\widetilde{g}^{e}<1$ & 0.055 & public education spending share of output \\
$0<\widetilde{g}^{i}<1$ & 0.041 & public investment spending share of output \\
$0<\widetilde{g}^{o}<1$ & 0.114 & other public investment spending share of output \\
$0<g^{e} / g<1$ & 0.262 & public education spending as a share of total $g$ \\
$0<g^{i} / g<1$ & 0.195 & public investment spending as a share of total $g$ \\
$0<g^{o} / g<1$ & 0.543 & other public spending as a share of total $g$ \\
$\sigma>1$ & 2.000 & $1 / \sigma$ is the intertemporal elasticity of consumption \\
$0 \leq \theta_{1} \leq 1$ & 0.600 & productivity of household human capital \\
$0 \leq 1-\theta_{1} \leq 1$ & 0.400 & productivity of aggregate human capital \\
$0 \leq \theta_{2} \leq 1$ & 0.200 & productivity of public education spending \\
$0<\tau<1$ & 0.210 & effective direct tax rate \\
\hline & &
\end{tabular}

The discount rate, $1 / \beta$ is equal to 1 plus the ex-post real interest rate,

\footnotetext{
${ }^{15}$ Note that an extensive sensitivity analysis of the calibration and its effects on the steady-state solution for the growth rate of output is provided in the Appendices.

${ }^{16}$ We calculate government investment net of education investment which is included in our $G^{e}$ measure.
} 
where the interest rate data is from the OECD Economic Outlook. This implies a value 0.964 for $\beta$. Again this figure is similar to other US studies, see e.g. King and Rebelo (1999), Lansing (1998) and Perli and Sakellaris (1998). The population gross growth rate $n$ is set equal to the post war labor force growth rate, 1.016, obtained by using data from Bureau of Labor Statistics. The depreciation rates for physical, $\delta^{p}$, and human capital, $\delta^{h}$, are calculated by Jorgenson and Fraumeni to be, on average, 0.049 and 0.0178, respectively. We also set the depreciation rate for public capital, $\delta^{g}$, equal to that of private capital.

We also require constants for government education, investment and other spending as shares of output. The education and investment spending ratios are fixed at sample averages using NIPA data to $\widetilde{g}^{e}=0.055, \widetilde{g}^{i}=0.041$. We set other government spending, $G_{t}^{o}$, in the government budget equation (16) so that the long-run solution for the tax rate gives 0.21 . This value corresponds to the effective income tax reported in the ECFIN dataset. ${ }^{17}$. This implies that $\widetilde{g}^{o}=(0.21-0.055-0.041)$. Finally the constants for the components of public spending to total public spending are also implied by the data, e.g. $g^{i} / g=0.195, g^{o} / g=0.543$, and $g^{e} / g \equiv 1-g^{i} / g-g^{o} / g=0.262$.

We next move on to the parameters of the production function of human capital. Note that the expression $\left(e_{t}^{h} H_{t}^{h}\right)^{\theta_{1}}\left(\bar{H}_{t}\right)^{1-\theta_{1}} B\left(g_{t}^{e}\right)^{\theta_{2}}$ in equation (9) is essentially the production function for the creation of new human capital, or what Jorgenson and Fraumeni (1992) call investment in human capital. The results for the base model are obtained by using the value for the human capital externality calibrated by Lucas (1988). Hence, we start by setting $\left(1-\theta_{1}\right)=0.4$. Conditional on this value, the productivity of household human capital, $\theta_{1}$, is determined residually and we then calibrate $\theta_{2}=0.2$ to ensure that the long-run gross growth rate of output per labour input is equal to 1.02. This value corresponds to the USA per labour input growth rate for 1949-1984 using GDP data from the NIPA accounts and labour data from Bureau of Labor Statistics. As there is no conclusive evidence on the size of human capital externalities, we will also examine the case of a much lower externality parameter, i.e. $\left(1-\theta_{1}\right)=0.05$, as calibrated by Tamura (1991).

We finally require model consistent values for the scale parameters $A$ and $B$. These are obtained by solving equations (5) and (12) using data averages and long-run values for the variables $y, k, k^{g}, e, \gamma$ and $g^{e}$, as well as the calibrated parameters $\alpha_{1}, \alpha_{2}, \theta_{1}, \theta_{2}, n$, and $\delta^{h}{ }^{18}$

\footnotetext{
${ }^{17}$ We calculate this as the weighted average of the effective tax rates on (gross) capital income and labor income, where the weights are capital's and labor's shares in income.

${ }^{18}$ For this exercise we obtain model consistent $y$ and $k^{g}$. In particular, $k^{g}$ is obtained from equation (18d), while $y$ is obtained from equation (18b), using NIPA data for $g^{i}$ (less education investment) and $c$. As a dataset for the share of time individuals spend on
} 


\section{Results}

In this section, using the solution of the second-order approximation of the model around the deterministic steady-state set out in the Appendix, we first examine the general equilibrium effects on steady-state growth and lifetime utility of increasing the public education spending share in the presence of both moderate and low human capital externalities. We then examine the transition paths to the steady-state when temporary shocks are applied to the innovations of the exogenous processes driving the public education and total factor productivity. ${ }^{19}$

\subsection{Growth and welfare}

The relationship between government size and economic growth is not monotonic. On one hand, governments provide growth promoting public goods and services and on the other, this provision requires taxes and distorts incentives. There is thus a trade-off being reflected in an inverted- $U$ curve (or a Laffer curve) between government size and economic growth (see, e.g. Barro 1990). After a critically large size, the costs of a larger public sector eventually outweigh the benefits. From a public policy perspective it is useful to have a handle on the magnitudes associated with the growth maximizing size of public education spending and also whether this is welfare maximizing. We therefore first calculate the steady-state growth rate associated with a range of shares of public education spending in GDP, for both policy regimes discussed in subsection 2.5.

For example, in Figure 1, subplot $(1,1)$, where $(1,1)$ refers to row and column numbers respectively, we derive the Laffer curve for the steady-state growth rate implied by our model under policy regime $\mathrm{A}$ and in subplot $(1,2)$ we derive the Laffer curve under policy regime B. Since an empirical consensus has not yet emerged on the exact size of human capital externalities, $\left(1-\theta_{1}\right)$, Figure 1 presents two graphs per subplot using range end-points for $\left(1-\theta_{1}\right)$ based on Lucas (1988) and Tamura (1991), e.g. 0.4 (solid blue line) and 0.05 (red line with a + marker) respectively.

We next derive the welfare maximizing size of government education spending (and the implied welfare maximizing size of the government as

education as opposed to working is not available, we obtain a proxy for $e$ to calibrate $B$. This is achieved by assuming that $e$ is the ratio of 16 years spent on average on education over 62 minus 6 years available on average for work or education.

${ }^{19}$ We have written extensive Matlab code to conduct this analysis and make use of the Matlab functions made available by Schmitt-Grohé and Uribe (2004) to solve and simulate the second-order approximation of the model. 
Figure 1: Effects of public education spending on steady-state growth and lifetime welfare
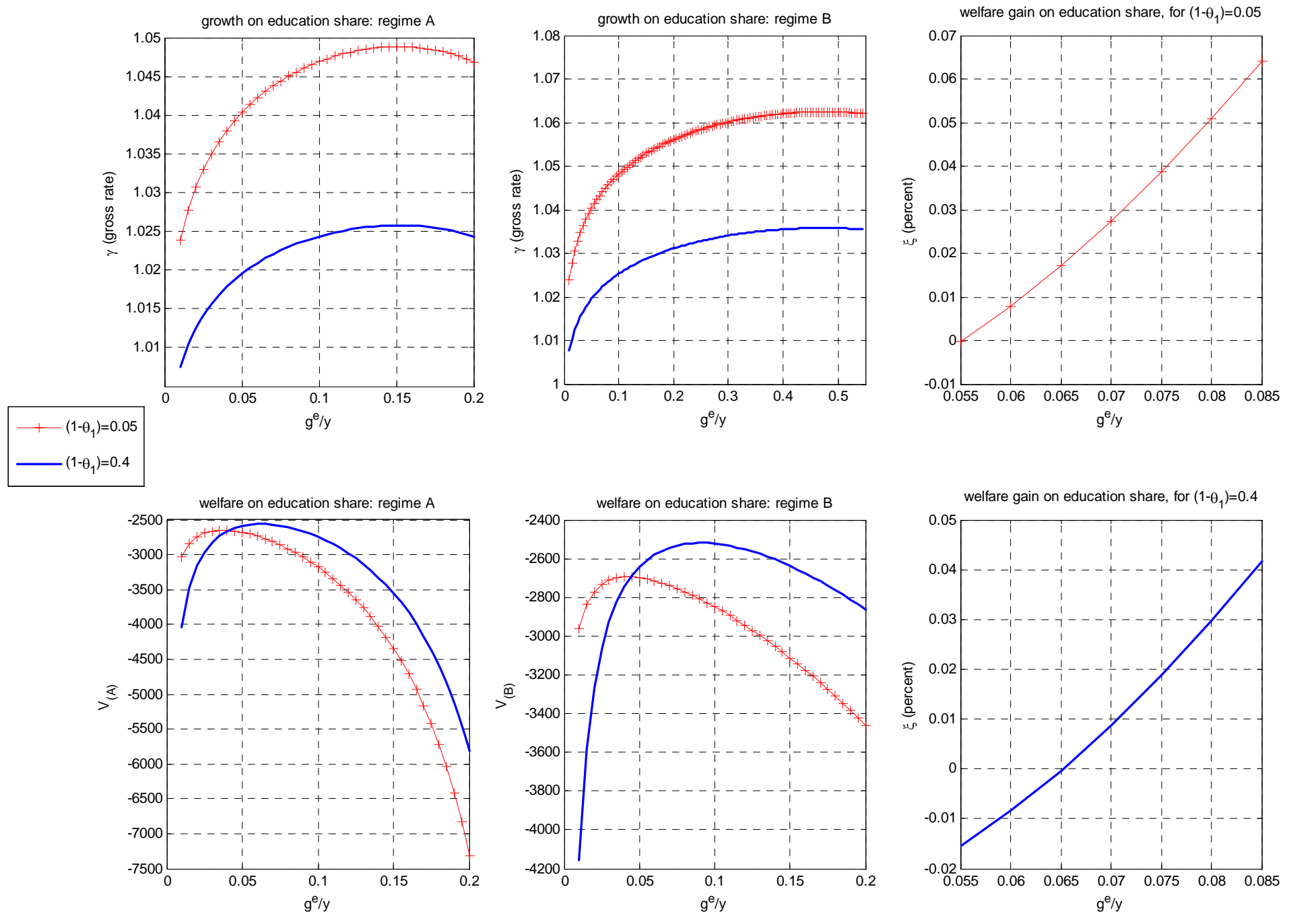
measured by total government spending as a share of output, $\tau$ ), where welfare is defined as the discounted sum of lifetime utility (see eq. (1)). To this end, we first undertake a second-order approximation of the within period utility function around the steady-state of the model (both defined in the Appendix). We then evaluate lifetime welfare for varying shares of public education spending (kept flat over time) using the solution(s) of the second order approximation to the stationary equilibrium laws of motion of the model which include equations $(18 a-22)$.

The welfare curves in Figure 1 are shown in subplots $(2,1)$ and $(2,2)$ for policy regimes $\mathrm{A}$ and $\mathrm{B}$ respectively. There are, again, two graphs per subplot for $\left(1-\theta_{1}\right)$ equal to 0.4 (solid blue line) and 0.05 (red line with a + marker) respectively. Finally, working as in e.g. Lucas (1990) we compute the welfare gains or losses associated with moving from the "base calibration" policy regime A to B. Recall that regime A is where the government increases productive and unproductive spending proportionately and regime $\mathrm{B}$ is where the government increases the productive spending on education only. Hence regime B implies that the long-run composition of government spending changes in favor of productive spending. Subplots $(1,3)$ and $(3,3)$ show $\xi$, which measures the welfare gains in terms of the percent of the consumption stream associated with policy $\mathrm{B}$ relative to $\mathrm{A}$, for a range of values for public education spending as a share of output, $\widetilde{g}^{e}$ (see the Appendix for the derivation of $\xi$ ). Subplot $(1,3)$ plots $\xi$ for the $\left(1-\theta_{1}\right)=0.05$ case while subplot $(2,3)$ is for $\left(1-\theta_{1}\right)=0.4$.

\subsubsection{Moderate externalities (as in Lucas, 1988)}

The Laffer curve in subplot $(1,1)$ suggests that, for policy regime A, the positive growth effects outweigh the disincentives of income taxation for increases in the public education share up to around $15 \%$ and imply a maximum growth rate of about $1.026 \%$. Relative to the steady-state in the base calibration of the model (i.e. $\widetilde{g}^{e}=5.5 \%$ and $\gamma=1.02 \%$ ) these imply changes of approximately 9.5 and about 0.01 percentage points respectively.

For policy regime B (see subplot $(1,2)$ ) the growth maximizing public education share is around $47 \%$ of GDP and the associated growth rate is $1.036 \%$, which imply changes of approximately 41.5 and 1.6 percentage points respectively. It is therefore immediately evident that there is much more scope for government intervention in the economy, if it takes the form of solely growth enhancing activities.

While the growth Laffer curves shows there is scope for growth promoting government spending, the welfare subplots $(2,1)$ and $(2,2)$ suggest that the welfare maximizing $\widetilde{g}^{e}$ share is less than the growth maximizing share. Under 
policy regime A (subplot $(2,1)$ ), the welfare maximizing $\widetilde{g}^{e}$ share is around $6.5 \%$, while, under policy regime B (subplot $(2,2)$ ), the welfare maximizing $\widetilde{g}^{e}$ share is around $8.5 \%$. The reason that the welfare Laffer curves peak earlier than the respective growth Laffer curves is that growth in this context has compositional effects on the economy. For example, while the increasing government size can enhance growth by allocating more social resources towards education, the associated higher tax rate decreases the post-tax labour and capital income and thus private consumption as a share of human capital, $c$, is crowded-out (see also below, Figure 2).

Finally, subplot $(2,6)$ suggests that there are important welfare gains from moving to policy regime $\mathrm{B}$, at least for $\widetilde{g}^{e}$ shares larger than $6.5 \%$ (which is the welfare maximizing $\widetilde{g}^{e}$ share under regime A). At the welfare maximizing $\widetilde{g}^{e}$ share under regime B (i.e. around $8.5 \%$ ), the welfare gains are as high as $4 \%$ of consumption.

\subsubsection{Low externalities (as in Tamura, 1991)}

The results reported in Figure 1 also suggest that the scope for government intervention is smaller if the human capital externality is lower (refer to the red line with a + marker in each subplot). In particular, in the presence of $\left(1-\theta_{1}\right)=0.05$, the growth maximizing $\widetilde{g}^{e}$ share is again at the same level as for the moderate externalities case. Also note that the growth rate is higher under lower externalities, for every level of government education spending, under both policy regimes. This is expected, as, under lower externalities, individual agents internalize more of the effects of their education effort on human capital. As we shall see below in Figure 2, the gap between the private and social returns is higher when externalities are higher, so that when externalities are higher, private education time is lower and hence the growth rate is lower.

However, as subplots $(2,1)$ and $(2,2)$ show, under lower externalities, the welfare curves peak earlier, so that, under both regimes, the welfare maximizing $\widetilde{g}^{e}$ share is about $3.5 \%$, which is within the range of historical data, but lower than the average historical level of public education spending. ${ }^{20}$ Hence, the lower the externalities, the less scope there is for welfare enhancing government involvement in education. Subplot $(1,3)$ again indicates that increases in $\widetilde{g}^{e}$ share under regime B again welfare dominate respective increases under regime A.

\footnotetext{
${ }^{20}$ We have conducted a sensitivity analysis of the level welfare maximizing $\widetilde{g}^{e}$ share with respect to the degree of externalities, and found that under regime A externalities of about $25 \%$ are necessary to justify a $\widetilde{g}^{e}$ share of $5.5 \%$ (the historical data average) as welfare maximizing. Under regime $\mathrm{B}$, respective externalities need to be approximately $15 \%$.
} 


\subsubsection{Policy, externalities and other stationary variables}

To further evaluate the importance of externalities for the effects of policy on the economy, we finally examine the long-run effects of increases in the $\widetilde{g}^{e}$ share on the other stationary variables of the model. These are shown in Figure 2 for both policy regimes. There are, again, two graphs per subplot for $\left(1-\theta_{1}\right)=0.4$ (solid blue line) and 0.05 (red line with a + marker) respectively, except for the the graphs for the tax rate, which is common under both cases. The first two rows of subplots in Figure 2 refers to regime A, while the other two refer to regime B. As can be seen, the effects are similar under both regimes.

Subplots $(1,1)$ and $(3,1)$ show that when externalities are higher, education effort $e$ is lower, reflecting that agents can effectively free ride on the human capital good. In other words, the more an individual agent's human capital depends on aggregate outcomes, the less private effort will be invested in education since the aggregate public good acts as a substitute for the private one.

The marginal values of consumption, $\lambda$ (subplots $(2,1)$ and $(4,1))$ and of education, $\psi$ (subplots $(2,2)$ and $(4,2)$ ) are lower in the steady-state in the presence of higher externalities. This is explained by the fact that when externalities are higher, the marginal private returns to investment are lower, as agents fail to internalize the increase in the marginal product of human and physical capital through the aggregate human capital term. In other words, the gap between the private and social returns is higher when externalities are higher.

Higher externalities also imply that $y$ (subplots $(1,3)$ and $(3,3))$ and $c$ (subplots $(1,2)$ and $(3,2)$ ) are higher. This follows since under higher externalities, the level of human capital can be increased with less education effort. Therefore, households choose to spend more time on work (see subplots $(2,1)$ and $(4,1))$ which in turn leads to higher output, labour income and consumption. Finally, note that the tax rate associated with maximum welfare under regime $\mathrm{A}$ is around $25 \%$, while under regime $\mathrm{B}$ it is around $24 \%$.

The results of the various exercises above suggest that increases in government size due to a rise in the share of productive expenditure produce plausible quantitative general equilibrium outcomes. In particular, the findings for both regimes regarding the Laffer curves appear consistent with other quantitative evidence, which finds positive growth effects of productive government spending in different cross-country and panel samples (see e.g. the papers by Easterly and Rebelo (1993), Devarajan et al. (1996) and Kneller et al. (1999)). 
Figure 2: Steady-state effects of public education spending for high and low externalities
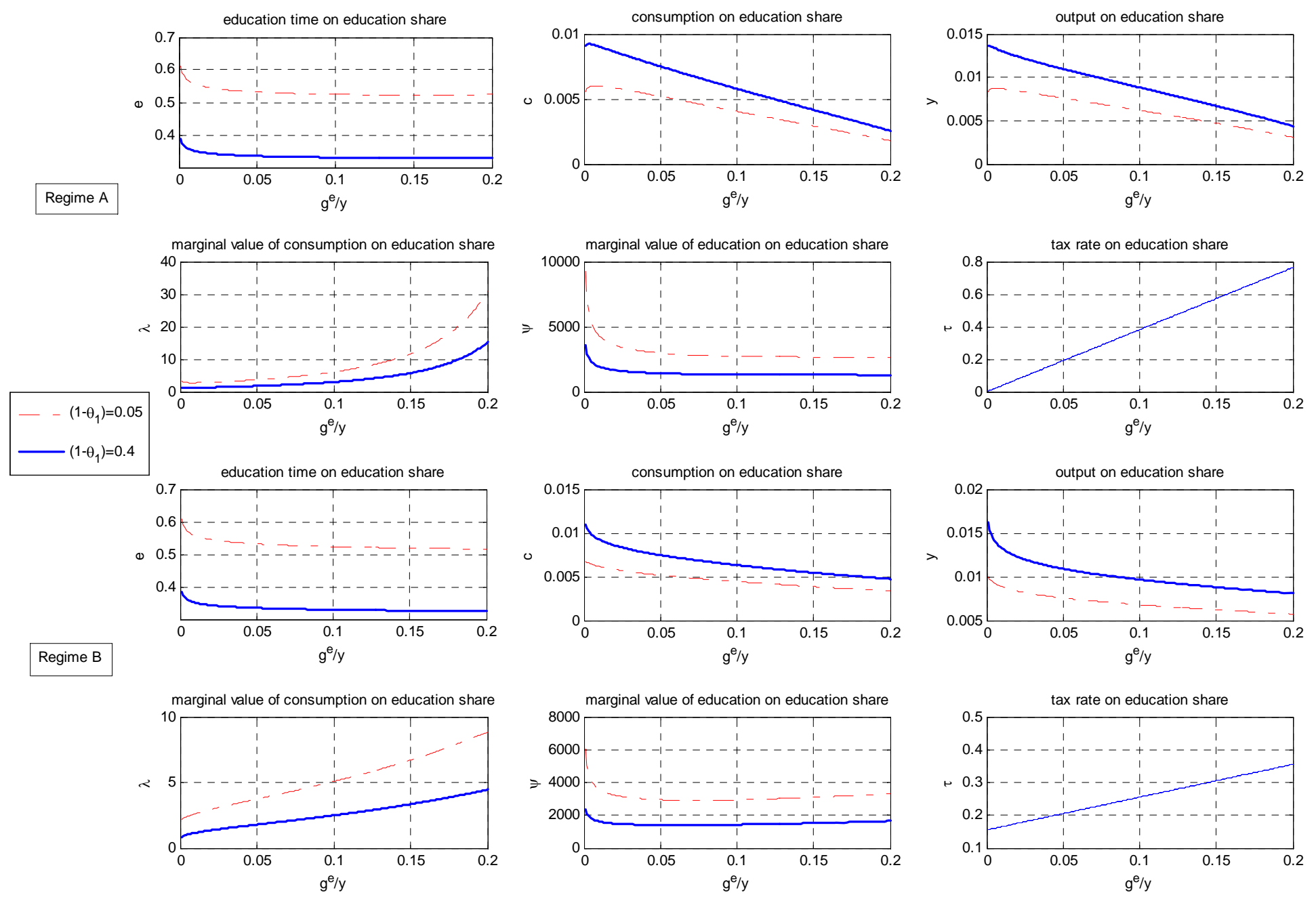


\subsection{Transitional dynamics}

Given that subsection 4.1 documents the steady-state effects of permanent increases in the public spending shares, we next turn to the dynamic properties of the model. To accurately gauge the persistence of the public spending shocks, we estimate the $A R(1)$ relation given by (22) using US NIPA data, where the log deviations are defined relative to a Hodrick-Prescott trend. The estimated values for $\rho^{e}$ is 0.442 and is significant at less than the $1 \%$ level of significance. The standard deviation of this process is 0.019 . Using a production function and time period similar to ours, Lansing (1988) provides estimates for TFP. Hence we use his parameters for the stationary TFP process in (23), e.g. $\rho=0.933$ and $\sigma_{a}=0.01$. Given that we have solved for a second order approximation of the model, we compute the impulse responses using the second order solution to the model (see the Appendix for details of the calculations involved).

\subsubsection{Education spending shock}

In Figure 3a, we start our analysis by examining the response to a standard deviation shock to $\widetilde{g}_{t}^{e}$ innovations (see eq. 22) for policy regime A. ${ }^{21}$ The last row of Figure 3a shows that this shock implies an increase in education spending, as well as the other stationary fiscal variables as shares of human capital (i.e. $g_{t}^{e}, g_{t}^{i}, g_{t}^{o}$ defined in eqs. (19) - (22)). As said above, this reflects the complementarities in the provision of public services. For example, if the government wishes to increase the number of teachers in the education sector, this will imply an increase in public administration support personnel. Or, if the government builds new schools, it will have to provide the corresponding infrastructure such as new roads and bridges to connect the new schools with the rest of the community.

The most important thing to note in Figure 2 is that an increase in $g_{t}^{e}$ (subplot $\left.(1,1)\right)$ generates a non-monotonic reaction in the growth rate, $\gamma_{t}$ (subplot $\left.(2,1)\right)$. Initially, the positive effects of increased human capital productivity outweighs the disincentives of higher taxation, $\tau_{t}$ (subplot $(4,3)$ ) so that education time, $e_{t}$ (subplot $(1,3)$ ) and hence $\gamma_{t}$ increase. However,

\footnotetext{
${ }^{21}$ We have also examined the impulse responses to a standard deviation shock to $\widetilde{g}_{t}^{e}$ innovations for policy regime B. The main qualitative results are the same as above, although, quantitatively, the effects of this shock on the economy are smaller. Under policy regime A, as expected, government spending education shocks have a much bigger effect on the overall size of the government and thus on the economy. This follows since increases in public education spending bring about complementary increases in the other components of government spending. To preserve space, we don't report these results but they are available on request.
} 

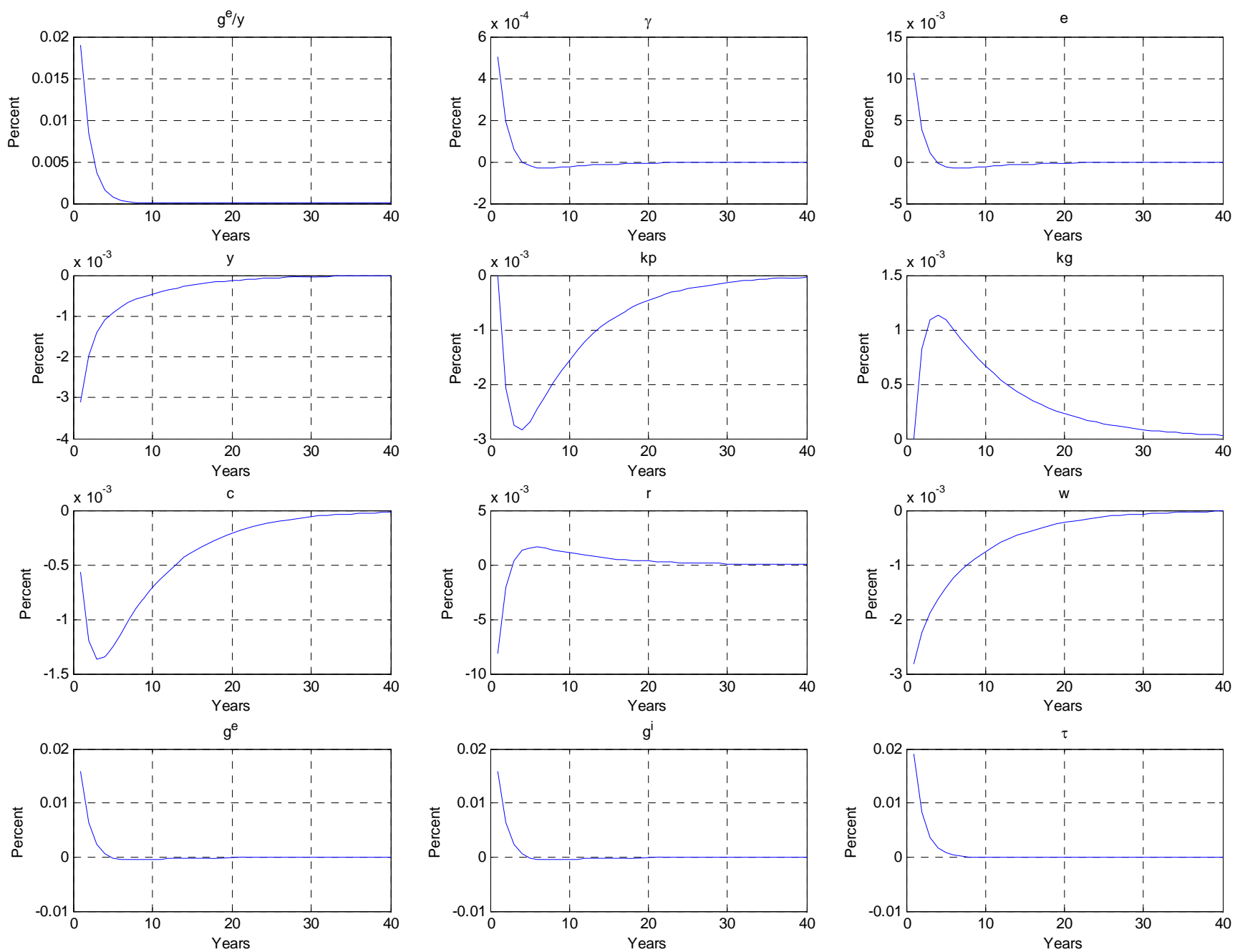
after the initial boom the negative effects dominate, thus the growth rate becomes lower than its steady-state value after four years and the economy converges to the steady-state from below.

Since $g_{t}^{e}$ enters the human capital production function directly (see eq. 5 ), human capital increases by more than output, consumption and private capital, so that these variables as shares of human capital, i.e. $y_{t}, c_{t}, k_{t}^{p}$ in subplots $(2,1),(3,1),(2,2)$, fall. In contrast, public capital (subplot $(2,3))$ increases as a share of human capital. This arises since government infrastructure investment, $g_{t}^{i}$ is proportional to $g_{t}^{e}$ (see last row of Figure 2) and $g_{t}^{i}$ in turn has a direct effect on public capital accumulation.

We finally examine the post-tax wage, $w_{t}$, subplot $(3,3)$ and interest rate, $r_{t}$, subplot $(3,2)$ after the education spending shock. For example, $w_{t}$ decreases, as the tax increase eliminates the benefits from the increase in productivity, so that the returns to the effective labour input fall. This also helps to understand the increase in education time, $e_{t}$, as households substitute work time for education, since the return to the latter is now higher. Further note that the reaction of the post tax return to capital is initially the same as the return to labour. However, it subsequently increases (as $y_{t}$ is increasing faster than $k_{t}^{p}$, see eq. 15) so that the post-tax interest rate converges to its steady-state value from above. This dynamic adjustment path can be understood by recognizing that there are there are two opposing effects on the post-tax return to capital, $r_{t}$. These include the negative effect resulting from the increased tax rate and the positive one from the increase in human capital. Given that human and physical capital are complements in the goods production (see eq. 12), increases in the former lead to increases in the latter. Thus it appears that the negative tax effect on $r_{t}$ dominates the positive human capital effect initially, but after 3-4 periods this is reversed.

\subsubsection{TFP shock}

In Figure 3b, we finally examine the responses of the key endogenous variables to a standard deviation shock to TFP innovations (see, eq. 23). This will help to contextualize the qualitative and quantitative importance of the education spending shock. ${ }^{22}$ The first thing to note is that, in the absence of the tradeoff associated with discretionary government education spending discussed above, the responses after the TFP shock are positive for the growth rate, output, consumption and private capital. The second important observation

\footnotetext{
${ }^{22}$ Note that the responses to TFP shocks are essentially the same under the two policy regimes. Again, to save space, these results are not reported here but will be made available on request.
} 

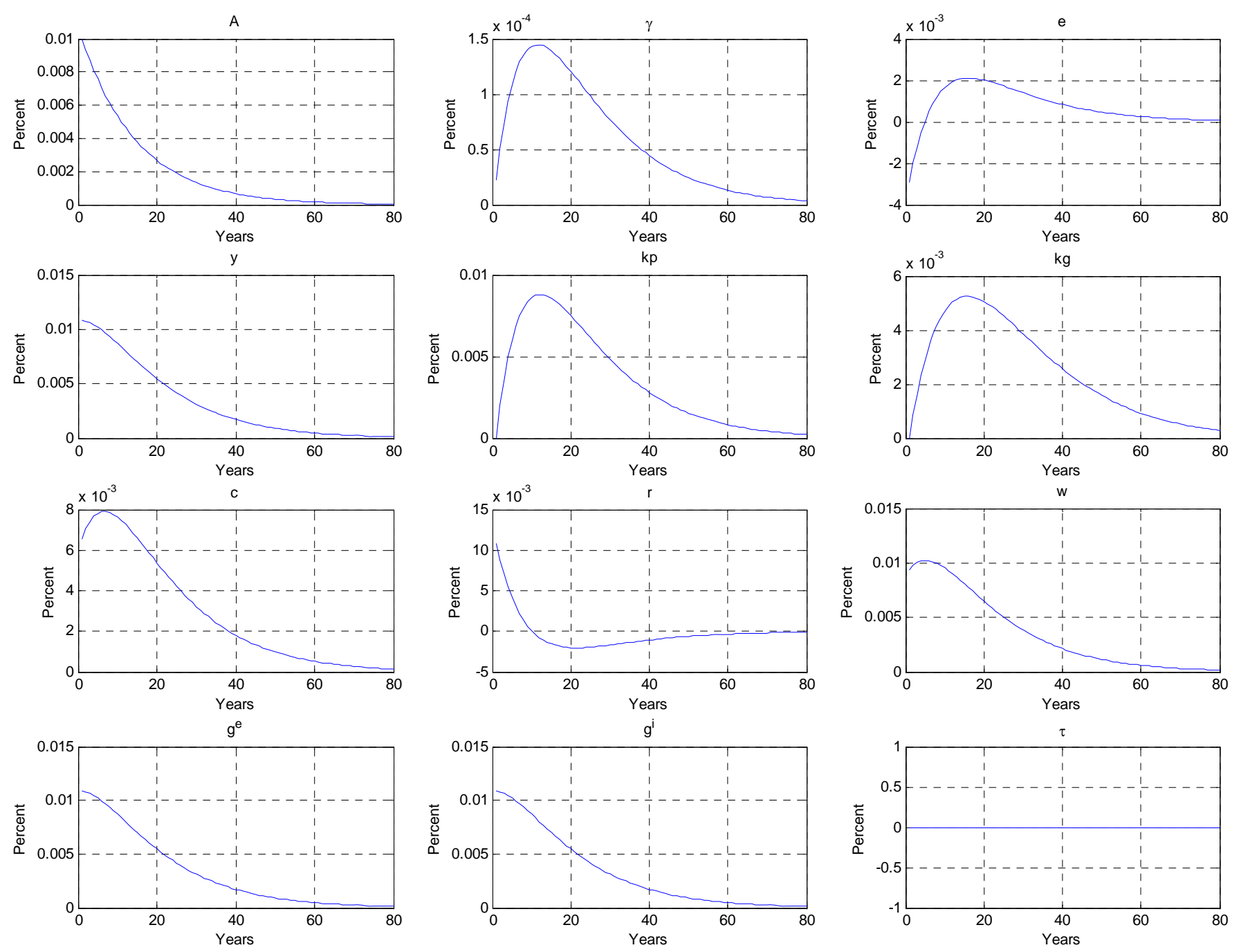
is that the quantitative magnitudes of the reactions are comparable for the standard deviation TFP and education spending shocks.

By definition, a positive TFP shock increases the productivity of both effective labour (see $w$ in subplot $(3,3)$ and physical capital (see $r$ in subplot $(3,2))$. Given the increase in $r$, investment in physical capital increases, as reflected by the increase in $k^{p}$ (subplot $(2,3)$ ). However, as $y_{t}$ is decreasing faster than $k_{t}^{p}, r$ (see eq. 15) falls below its steady-state value and converges to this from below. Regarding $w$, its initial effect is to decrease education time, $e$ (subplot $(1,3)$ ), as households want to work more to receive the higher wage, but the increased return to human capital implies that they also want to educate more, so that after the initial drop, $e$ is increased and this helps to sustain the increase in the growth rate for about 15 years.

Since, via the production function for goods (see eq. 12), the effect of TFP on physical goods production is direct, output increases by more than human capital, so that $y$ (subplot $(2,1)$ ) increases. As consumption (subplot $(3,1))$ is a normal good, it follows income by increasing, although by a smaller amount. This is the standard consumption smoothing result.

In this exercise, the tax rate, $\tau_{t}$ (subplot $(3,3)$ ) has not increased, but as income increases, tax revenue increase, so that government spending as a share of human capital is higher after the TFP shock (see last row of Figure 3). This also implies that public capital as a share of human capital increases.

\section{Conclusions}

In this paper we have examined the importance of public education spending, under human capital externalities, for aggregate outcomes. In particular, we found that public spending on education is generally growth and welfare promoting and have documented the magnitudes for the size of human capital externalities over which this occurs.

The results of our base calibration (Regime A), under moderate sized externalities, suggest that the growth rate of the economy over our sample would have been higher by about 0.01 of a point if the education spending share of output was $15 \%$ instead of its historical average of $5.5 \%$. However, given that pubic education spending crowds-out private consumption, the welfare maximising size of the government is found to be $6.5 \%$. Thus, it appears that these is some scope for increasing welfare gains by raising public education's share in output.

We next found that there are potentially further welfare gains to be made if the composition of public spending can be altered in favour of education spending relative to the other components of total government spending (i.e. 
Regime B). These welfare increases, calculated using the solution to the second order approximation of the model, amount to 4 percent of consumption and correspond to an education spending share of $8.5 \%$.

Another main finding is that the positive welfare effects of education spending work through human capital externalities. In particular, in the presence of higher externalities, the model predicts that the welfare maximizing education spending is higher. Since there is a larger gap between private and social returns under higher externalities, government intervention is more beneficial.

Finally, we found that a positive education spending shock generates a non-monotonic reaction in the growth rate and other key economic variables, so that after an initial boom there is a decrease in the growth rate below its steady-state value. The quantitative effects of discretionary fiscal policy of this form were found to be quite important, since they were similar in magnitude to those of a standard TFP shock.

Thus the general message arising from this study is that public education spending policy is indeed quantitatively important for macroeconomic outcomes and that human capital externalities are significant in determining these. Therefore, more research is needed to assess the empirically relevant magnitude of human capital externalities and to further evaluate the different possible channels through which these shape the effects of education policies in modern economies.

\section{References}

[1] Aghion P. and P. Howitt (1998): Endogenous Growth Theory. The MIT Press. Cambridge, Mass.

[2] Azariadis C. and A. Drazen (1990): Threshold externalities in economic development, Quarterly Journal of Economics, 105, 501-526.

[3] Baier S. and G. Glomm (2001): Long-run growth and welfare effects of public policies with distortionary taxation, Journal of Economic Dynamics and Control, 25, 2007-2042.

[4] Barro R. (1990): Government spending in a simple model of endogenous growth, Journal of Political Economy, 98, S103-S125.

[5] Barro R. (1991): Economic growth in a cross section of countries, Quarterly Journal of Economics, 106, 407-43. 
[6] Barro R. (2001): Human capital and growth, American Economic Review, $91,12-17$.

[7] Barro R. and J. W. Lee (2001): International data on educational attainment: updates and implications, Oxford Economic Papers, 53, 541-563.

[8] Barro R. and X. Sala-i-Martin (2004): Economic Growth, Second edition, The MIT Press, Cambridge, Mass.

[9] Baxter M. and R. King (1993): Fiscal policy in general equilibrium, American Economic Review, 83: 315-334.

[10] Benhabib J. and M. Spiegel (1994): The Role of Human Capital in Economic Development: Evidence from Aggregate Cross-Country Data, Journal of Monetary Economics, 34, 143-73.

[11] Benhabib J. and R. Perli (1994): Uniqueness and indeterminacy: On the dynamics of endogenous growth, Journal of Economic Theory, 63, 113-142.

[12] Bils M. and P. Klenow (2000): Does schooling cause growth?, American Economic Review, 90, 1160-1183.

[13] Blankenau W. and N. Simpson (2004): Public education expenditures and growth, Journal of Development Economics, 583-605.

[14] Blankenau W. (2005): Public schooling, college education and growth, Journal of Economic Dynamics and Control, 29, 487-507.

[15] Davies J. (2003): Empirical evidence on human capital externalities, Working Paper no. 2003-5, Economic Policy Research Institute.

[16] de la Fuente A. and R. Domenech (2001): Schooling data, technological diffusion and the neoclassical model, American Economic Review, 91, 323-327.

[17] Devarajan S., V. Swaroop and H. Zoo (1996): The composition of public expenditure and economic growth, Journal of Monetary Economics, 37, 313-344.

[18] Easterly W. and S. Rebelo (1993): Fiscal policy and economic growth: An empirical investigation, Journal of Monetary Economics, 32, 417458. 
[19] Gemmel N. and R. Kneller (2001): The impact of fiscal policy on longrun growth, European Economy, 1, 98-129.

[20] Gong G., A. Greiner and W. Semmler (2004): The Uzawa-Lucas model without scale effects: theory and empirical evidence, Structural Change and Economic Dynamics, 15, 401-420.

[21] Glomm G. and B. Ravikumar (1992): Public versus private investment in human capital: endogenous growth and income inequality, Journal of Political Economy, 100, 818-834.

[22] Glomm G. and B. Ravikumar (1994): Public investment in infrastructure in a simple growth model, Journal of Economic Dynamics and Control, 18, 1173-1187.

[23] Glomm G. and B. Ravikumar (1997): Productive government expenditures and long-run growth, Journal of Economic Dynamics and Control, $21,183-204$.

[24] Heckman J. and P. Klenow (1997): Human capital policy, University of Chicago, mimeo.

[25] Jorgenson D. and B. Fraumeni, (1992b): Investment in education and U.S. economic growth, Scandinavian Journal of Economics, 94, S51-S70.

[26] Jorgenson D. and B. Fraumeni, (1992a): The output of the education sector, in Z. Griliches (ed.) Output Measurement in the Services Sector, Studies in Income and Wealth, Vol. 55, Chicago, University of Chicago Press.

[27] Jorgenson D. and B. Fraumeni, (1989): The accumulation of human and nonhuman capital, 1948-1984, in R.E. Lipsey and H.S. Tice (eds.), The Measurement of Saving, Investment and Wealth, Studies in Income and Wealth, Vol. 52, Chicago, University of Chicago Press.

[28] Kim J. and S. Kim (2003): Spurious welfare reversals in international business cycle models, Journal of International Economics, Elsevier, 60, 471-500.

[29] King R. and S. Rebelo (1999): Resuscitating real business cycles, in Handbook of Macroeconomics, vol. 1B, edited by J. Taylor and M. Woodford, North Holland. 
[30] King R., Plosser, C. I. and Rebelo, S. T. (1988): Production, growth and business Cycles, II. New Directions, Journal of Monetary Economics, 21, 309-341.

[31] Klenow P. and R. Rodrigues-Clair (2005): Externalities and growth, in Handbook of Economic Growth, vol. 1A, edited by P. Aghion and S. Durlauf, North Holland.

[32] Koop G., H. Pesaran and S. Potter (1996): Impulse response analysis in nonlinear multivariate models, Journal of Econometrics, 74, 119-147.

[33] Kneller R., M. Bleaney and N. Gemmel (1999): Public policy and the government budget constraint, Journal of Public Economics, 74, 171190.

[34] Lansing K. (1998): Optimal fiscal policy in a business cycle model with public capital, Canadian Journal of Economics, 31: 337-364.

[35] Lucas R. E. (1988): On the mechanics of economic development, Journal of Monetary Economics, 22, 3-42.

[36] Lucas R. E. (1990): Supply-side economics: An analytical review, Oxford Economic Papers, 42, 293-316.

[37] Lucas R. E. (2002): Lectures on Economic Growth, Harvard University Press, Cambridge, Massachusetts and London, England.

[38] Malley J., A. Philippopoulos and U. Woitek (2007): Electoral uncertainty, fiscal policy and macroeconomic fluctuations, Journal of Economic Dynamics and Control, (in press).

[39] Mamuneas, T., P. Kalaitzidakis, A. Savvides and T. Stengos (2001): Measures of human capital and nonlinearities in economic growth, Journal of Economic Growth, 6, 229-254.

[40] Mankiw G., Romer D. and D. Weil (1992): A contribution to the empirics of economic growth, Quarterly Journal of Economics, 107, 402-37.

[41] Martinez-Mongay C. (2000): ECFIN's effective tax rates. Properties and comparisons with other tax indicators, DG ECFIN Economic Papers, No 146, Brussels: European Commission.

[42] Mueller D. (2003): Public Choice III, Cambridge University Press, Cambridge. 
[43] Ortigueira S. (1998): Fiscal policy in an endogenous growth model with human capital accumulation, Journal of Monetary Economics, 42, 323355.

[44] Park H. and A. Philippopoulos (2003): On the dynamics of growth and fiscal policy with redistributive transfers, Journal of Public Economics, 87, 515-538.

[45] Park H. and A. Philippopoulos (2004): Indeterminacy and fiscal policies in a growing economy, Journal of Economic Dynamics and Control, 28, 645-660.

[46] Perli R. and P. Sakellaris (1998): Human capital formation and business cycle persistence, Journal of Monetary Economics, 42, 67-92.

[47] Romer P. M. (1986): Increasing returns and long-run growth, Journal of Political Economy, 94, 1002-1037.

[48] Romer P. M. (1990): Human capital and growth: theory and evidence, Carnegie-Rochester Conference Series on Public Policy, 32, 251-286.

[49] Schmitt-Grohé S. and M. Uribe (2004): Solving dynamic general equilibrium models using a second-order approximation to the policy function, Journal of Economic Dynamics and Control, 28, 755-775.

[50] Stokey N. and S. Rebelo (1995): Growth effects of flat-rate taxes, Journal of Political Economy, 105, 519-550.

[51] Su X. (2004): The allocation of public funds in a hierarchical educational system, Journal of Economic Dynamics and Control, 28, 2485-2510.

[52] Tamura R. (1991): Income convergence in an endogenous growth model, Journal of Political Economy, 99, 522-540.

[53] Tanzi V. and H. Zee (1997): Fiscal policy and long-run growth, IMF Staff Papers, 44, 179-209.

[54] Temple J. (2001): Generalizations that aren't? Evidence on education and growth, European Economic Review, 45, 905-918.

[55] Turnovsky S. and W. Fisher (1995): The composition of government expenditure and its consequence for macroeconomic performance, Journal of Economic Dynamics and Control, 19, 747-786. 


\section{Appendices}

\subsection{Steady-state of DCE}

In the absence of stochastic shocks to $A_{t}$ and $g_{t}^{e}$ for all $t$, the economy converges to its steady-state in which the stationary variables defined in subsection 2.4 are constant (i.e. for any $x_{t}, x$ denotes its long-run value). Since our model's steady-state does not have an analytic solution, its numeric solution implied by the parameters values in Table 1 is reported in Appendix Table 1. With the exception of the steady-state growth rate, $\gamma$, and the share of time allocated to education, $e$, all endogenous variables are reported as shares of both $\bar{H}_{t}$ and $\bar{Y}_{t}$. Given that the normalization with respect to $\bar{H}_{t}$ is less familiar to most readers, the shares with respect to $\bar{Y}_{t}$ are included to help contextualize the results relative to others reported in the literature.

\begin{tabular}{cccc}
\hline \multicolumn{4}{c}{ Appendix Table 1: Steady-state } \\
\hline \hline variable & Shares of $\bar{H}_{t}$ & variable & Shares of $\bar{Y}_{t}$ \\
$\gamma$ & 1.02 & n.a. & n.a. \\
$e$ & 0.3343 & n.a. & n.a \\
$y=\frac{\bar{Y}}{\bar{H}}$ & 0.0107 & $\frac{y}{y}$ & 1.0000 \\
$c=\frac{\bar{C}}{\bar{H}}$ & 0.0073 & $\frac{c}{y}$ & 0.6826 \\
$k^{p}=\frac{\bar{K}^{p}}{\bar{H}^{g}}$ & 0.0279 & $\frac{k^{p}}{y}$ & 2.5924 \\
$k^{g}=\frac{\bar{K}^{g}}{\bar{H}}$ & 0.0051 & $\frac{k^{g}}{y}$ & 0.4768 \\
\hline
\end{tabular}

Further note that our calibration does not produce a multiplicity of solutions. This finding is documented in Appendix Figure 1 below which shows the sensitivity of the steady-state growth rate to a range of values for every parameter in the model. These ranges cover the values found in the relevant calibration and estimation literatures. As expected, the elasticity of output growth with respect to the scale parameters $A, B$ and $\theta_{2}$ is the greatest, otherwise the output growth response works in the expected direction and is not overly sensitive to any parameter in the model. 


\section{Appendix Figure 1: Partial effects of changes in the parameters on $\gamma$}
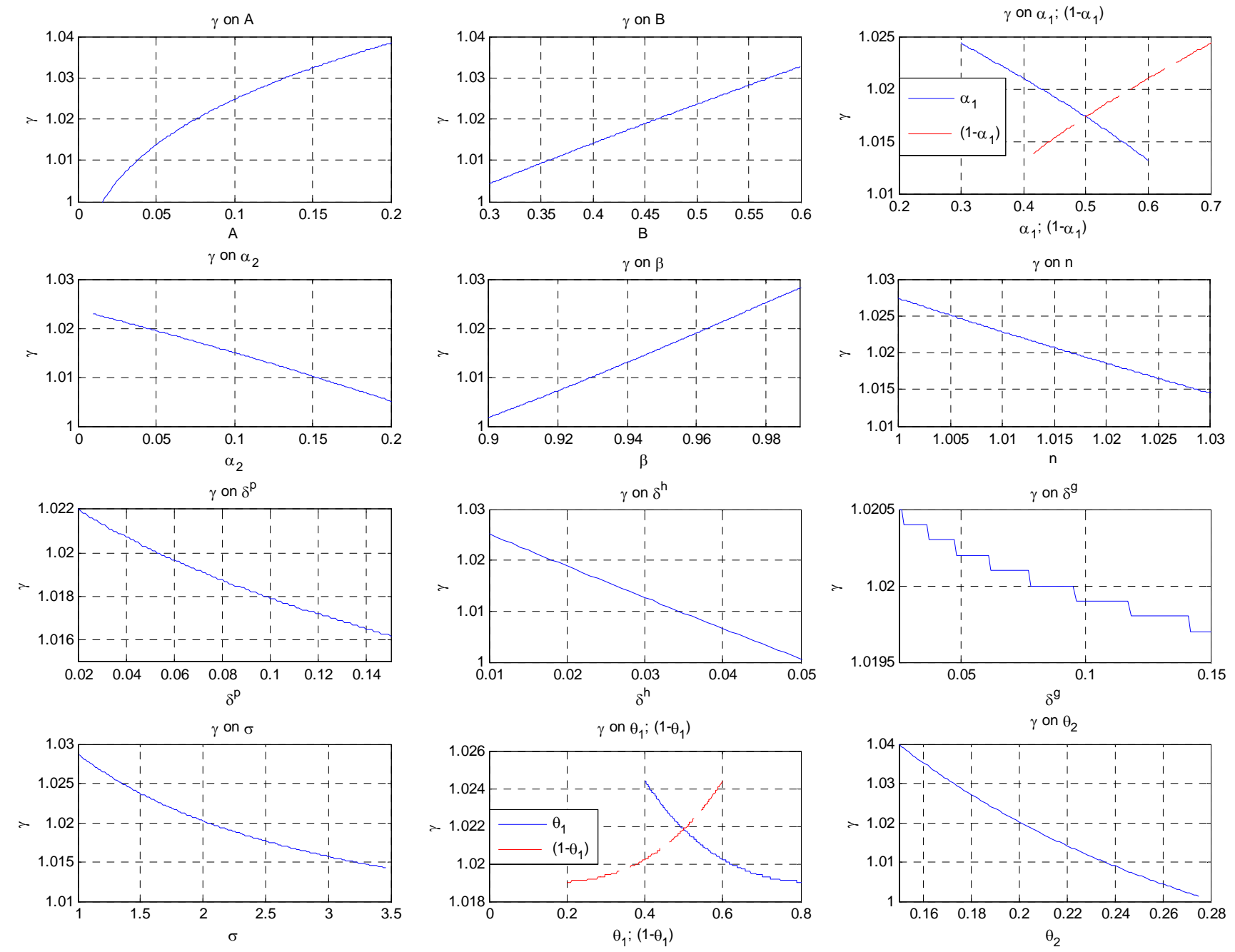


\section{Welfare}

\subsection{Within-period utility function}

Using the notation set out in the paper, first consider the per capita representation of the instantaneous CRRA-utility function given by (2)

$$
\bar{U}_{t}=\frac{\bar{C}_{t}^{1-\sigma}}{1-\sigma}
$$

or using our notation for stationary variables

$$
\bar{U}_{t}=\frac{\left(c_{t} \bar{H}_{t}\right)^{1-\sigma}}{1-\sigma}
$$

where $c_{t} \equiv\left(\frac{\bar{C}_{t}}{\bar{H}_{t}}\right)$, is stationary consumption and $\bar{H}_{t}$ is the beginning-ofperiod capital stock. From the definition of the growth rate, $\gamma_{t} \equiv \bar{H}_{t+1} / \bar{H}_{t}$ it follows that for $t \geq 1$

$$
\bar{H}_{t}=\bar{H}_{0}\left(\prod_{s=0}^{t-1} \gamma_{s}\right)
$$

where $\bar{H}_{0}$ is given from initial conditions.

Substituting $(A 3)$ into $(A 2)$ gives

$$
\begin{gathered}
\bar{U}_{t}=\frac{\left(\bar{H}_{0} c_{t}\left(\prod_{s=0}^{t-1} \gamma_{s}\right)\right)^{1-\sigma}}{1-\sigma} \text { for } t \geq 1 \\
\bar{U}_{0}=\frac{\left(\bar{H}_{0} c_{0}\right)^{1-\sigma}}{1-\sigma} \text { for } t=0 .
\end{gathered}
$$

\subsection{Utility at the steady-state}

We next define the long-run as the state without stochastic shocks which implies that stationary variables are constant. Thus using $(A 4 . a, b)$, utility at the steady-state can be written as

$$
\bar{U}_{t}^{*}=\frac{\left(\bar{H}_{0} c \gamma^{t}\right)^{1-\sigma}}{1-\sigma} \text {. }
$$

where the ${ }^{*}$ superscript denotes steady-state per capita utility. In the steadystate, non-stationary $\bar{C}_{t}$ grows at the constant rate $\gamma$, which in turn implies for $\sigma, \gamma>1$ that the growth of $\bar{U}_{t}^{*}$ is constant and less than unity. 


\subsection{Approximate within-period utility}

\subsubsection{Time $t \geq 1$}

The second-order approximation of $(A 4 . a)$ around (A5) is given by

$$
\begin{aligned}
\bar{U}_{t}^{s} \simeq & \bar{U}_{t}^{*}+\left[\bar{U}_{c} c\right] \widehat{c}_{t}+\frac{1}{2}\left\{\left[\bar{U}_{c} c+\bar{U}_{c c} c^{2}\right] \widehat{c}_{t}^{2}\right\} \\
& +\left[\bar{U}_{\gamma} \gamma\right]\left(\widehat{\gamma}_{0}+\widehat{\gamma}_{1}+\ldots+\widehat{\gamma}_{t-1}\right)+\frac{1}{2}\left\{\left[\bar{U}_{\gamma} \gamma+\bar{U}_{\gamma \gamma} \gamma^{2}\right] \times\right. \\
& \left(\left[\widehat{\gamma}_{0}^{2}+\widehat{\gamma}_{1}^{2}+\ldots+\widehat{\gamma}_{t-1}^{2}\right)\right\}+\left[\bar{U}_{c \gamma} c \gamma\right]\left(\widehat{c}_{t} \widehat{\gamma}_{0}+\widehat{c}_{t} \widehat{\gamma}_{1}+\ldots+\widehat{c}_{t} \widehat{\gamma}_{t-1}\right)+ \\
& +\left[\bar{U}_{\gamma_{i, j}} \gamma^{2}\right]\left\{\left(\widehat{\gamma}_{0} \widehat{\gamma}_{1}+\widehat{\gamma}_{0} \widehat{\gamma}_{2}+\ldots+\widehat{\gamma}_{0} \widehat{\gamma}_{t-1}\right)+\left(\widehat{\gamma}_{1} \widehat{\gamma}_{2}+\widehat{\gamma}_{1} \widehat{\gamma}_{2}+\ldots+\right.\right. \\
& \left.\left.\widehat{\gamma}_{1} \widehat{\gamma}_{t-1}\right)+\ldots+\left(\widehat{\gamma}_{t-2} \widehat{\gamma}_{t-1}\right)\right\}+O[3]
\end{aligned}
$$

where for any variable $x_{t}, \widehat{x}_{t} \equiv \ln \left(x_{t} / \bar{x}\right) ; \frac{x_{t}-\bar{x}}{\bar{x}} \simeq \widehat{x}_{t}+\frac{1}{2}\left(\widehat{x}_{t}\right)^{2}$; the $s$ superscript denotes the 2nd-order approximation to utility; $O[3]$ contains all terms of order higher than two; and the 1st- and 2nd-partial derivatives of (A4.a) evaluated at the steady-state. In what follows, consistent with the literature, we set $O[3]=0$.

We start by finding, for any $t \geq 1$, the second-order approximation of (A4.a) wrt to $c$,

$$
\bar{U}_{t, c}^{s}=\bar{U}_{t}^{*}+\left(\bar{H}_{0} c \gamma^{t}\right)^{1-\sigma}\left[\widehat{c}_{t}+\frac{1}{2}(1-\sigma) \widehat{c}_{t}^{2}\right] .
$$

We next obtain the same for $\gamma_{t}$,

$$
\bar{U}_{t, \gamma}^{s} \simeq\left(\bar{H}_{0} c \gamma^{t}\right)^{1-\sigma}\left[\sum_{s=0}^{t-1} \widehat{\gamma}_{s}+\frac{1}{2}(1-\sigma) \sum_{s=0}^{t-1} \widehat{\gamma}_{s}^{2}\right] .
$$

Finally we find the second order approximation associated with all the cross products terms,

$$
\bar{U}_{t, c \gamma}^{s}=\left[(1-\sigma)\left(K_{0} \bar{c} \gamma^{t}\right)^{1-\sigma}\right]\left[\widehat{c}_{t} \sum_{s=0}^{t-1} \widehat{\gamma}_{s}\right]
$$

and

$$
\bar{U}_{t, \gamma_{i, j}}^{s}=\left[(1-\sigma)\left(\bar{H}_{0} c \gamma^{t}\right)^{1-\sigma}\right] \sum_{j=0}^{t-2}\left(\widehat{\gamma}_{j} \sum_{s=j+1}^{t-1} \widehat{\gamma}_{s}\right) .
$$

Combining (A6.1), (A6.2), (A6.3) and $(A 6.4)$ we can thus write the second-order approximation of $(A 4 . a)$ using the general form provided by 
(A.6) for $t \geq 1$ as

$$
\begin{aligned}
\bar{U}_{t}^{s} \simeq & \bar{U}_{t}^{*}+\left(\bar{H}_{0} c \gamma^{t}\right)^{1-\sigma} \times \\
& {\left[\widehat{c}_{t}+\frac{1}{2}(1-\sigma) \widehat{c}_{t}^{2}+\sum_{s=0}^{t-1} \widehat{\gamma}_{s}+\frac{1}{2}(1-\sigma) \sum_{s=0}^{t-1} \widehat{\gamma}_{s}^{2}+\right.} \\
& \left.(1-\sigma) \widehat{c}_{t} \sum_{s=0}^{t-1} \widehat{\gamma}_{s}+(1-\sigma) \sum_{j=0}^{t-2}\left(\widehat{\gamma}_{j} \sum_{s=j+1}^{t-1} \widehat{\gamma}_{s}\right)\right]
\end{aligned}
$$

\subsubsection{Time $t=0$}

The second-order approximation of $(A 4 . b)$ around $(A 5)$ for $t=0$ is given by

$$
\bar{U}_{0, c}^{s} \simeq \bar{U}_{o}^{*}+\left[\bar{U}_{0, c} c\right] \widehat{c}_{0}+\frac{1}{2}\left\{\left[\bar{U}_{0, c} c+\bar{U}_{0, c c} c^{2}\right] \widehat{c}_{0}^{2}\right\}
$$

or

$$
\bar{U}_{0}^{s} \simeq \frac{\left(\bar{H}_{0} c\right)^{1-\sigma}}{1-\sigma}+\left(\bar{H}_{0} c\right)^{1-\sigma}\left[\widehat{c}_{0}+\frac{1}{2}(1-\sigma) \widehat{c}_{0}^{2}\right] .
$$

\subsection{Second-order approximation of expected lifetime utility}

Lifetime welfare, $V$, is defined as the present discounted value of lifetime utility, i.e. $\left(A 7^{\prime}\right)$ plus the expected value of the infinite discounted sum of $\left(A 6^{\prime}\right)$

$$
V \simeq \bar{U}_{0}^{s}+E_{0}\left[\sum_{t=1}^{\infty} \beta^{t} \bar{U}_{t}^{s}\right]
$$

or

$$
\begin{aligned}
V \simeq & \frac{\left(\bar{H}_{0} c\right)^{1-\sigma}}{1-\sigma}+\left(\bar{H}_{0} c\right)^{1-\sigma}\left[\widehat{c}_{0}+\frac{1}{2}(1-\sigma) \widehat{c}_{0}^{2}\right]+ \\
& E_{0} \sum_{t=1}^{\infty} \beta^{t}\left\{\frac{\left(\bar{H}_{0} c \gamma^{t}\right)^{1-\sigma}}{1-\sigma}+\left(\bar{H}_{0} c \gamma^{t}\right)^{1-\sigma}\left[\widehat{c}_{t}+\frac{1}{2}(1-\sigma) \widehat{c}_{t}^{2}+\sum_{s=0}^{t-1} \widehat{\gamma}_{s}+\right.\right. \\
& \left.\frac{1}{2}(1-\sigma) \sum_{s=0}^{t-1} \widehat{\gamma}_{s}^{2}+(1-\sigma) \widehat{c}_{t} \sum_{s=0}^{t-1} \widehat{\gamma}_{s}+(1-\sigma) \sum_{j=0}^{t-2}\left(\widehat{\gamma}_{j} \sum_{s=j+1}^{t-1} \widehat{\gamma}_{s}\right)\right]
\end{aligned}
$$

In the simulations $T=300$ and the sample average for $V$ is calculated using 500 simulations. ${ }^{23}$

\footnotetext{
${ }^{23}$ Note that for our annual rate of time preference, $\beta=0.964, V_{T} \simeq 0$ for $T=300$. In contrast, studies using quarterly data with $\beta=0.99, T=1000$ is required.
} 


\subsubsection{Welfare comparisons}

Let $\bar{C}_{t}^{A}$ denote the contingent plan for per capita consumption associated with regime $A$ and $\bar{C}_{t}^{B}$ the contingent plan for per capita consumption associated with regime $B$. We can then, following e.g. Lucas (1990), define $\xi$ as the fraction of regime $B$ 's consumption process that a household would be willing to give up to be as well off under regime $A$ as under $B$. Hence, we can write:

$$
\begin{aligned}
V_{(A)} & =E_{0}\left\{\sum_{t=0}^{\infty} \beta^{t} \bar{U}_{t}\left[\bar{C}_{t}^{B}(1-\xi)\right]\right\} \\
& =E_{0}\left\{\sum_{t=0}^{\infty} \beta^{t}\left[\frac{\left(\bar{C}_{t}^{B}\right)^{1-\sigma}}{1-\sigma}(1-\xi)^{1-\sigma}\right]\right\} \\
& =(1-\xi)^{1-\sigma} E_{0}\left\{\sum_{t=0}^{\infty} \beta^{t}\left[\frac{\left(\bar{C}_{t}^{B}\right)^{1-\sigma}}{1-\sigma}\right]\right\} \\
& =(1-\xi)^{1-\sigma} V_{(B)} .
\end{aligned}
$$

Solving for $\xi$ we then obtain:

$$
\begin{aligned}
V_{(A)} & =(1-\xi)^{1-\sigma} V_{(B)} \\
& \Rightarrow \ln (1-\xi)=\frac{1}{1-\sigma} \times \ln \left(\frac{V_{(A)}}{V_{(B)}}\right) \\
& \Rightarrow \xi \simeq \frac{1}{1-\sigma} \times \ln \left(\frac{V_{(B)}}{V_{(A)}}\right)
\end{aligned}
$$

where, $V_{(B)}$ and $V_{(A)}$ are calculated using the second order approximation of welfare defined in $\left(A 8^{\prime}\right)$ averaged over 500 simulations.

\subsection{Computation of second-order impulse response func- tions}

Our IRFs are computed using the following setup (see, e.g. Koop, Pesaran and Potter (1996))

$$
\operatorname{IRF}\left(p, \sigma^{i}, 0\right)=\frac{E_{t}\left[\mathbf{y}_{t+p}\left|\sigma^{i} ; \mathbf{I}_{0}\right|\right]-E\left[\mathbf{y}_{t+p}\left|\mathbf{I}_{0}\right|\right]}{E\left[\mathbf{y}_{t+p}\left|\mathbf{I}_{0}\right|\right]}
$$

where $\mathbf{y}$ denotes our vector of endogenous state and co-state variables; $\sigma^{i}$ represents the standard deviation of the $i^{\text {th }}$ innovation, $\varepsilon^{i} ; i=1,2$ refers 
to $\varepsilon^{e}$ and $\varepsilon^{a}$ respectively; and $\mathbf{I}_{0}$ is the information set available at time 0 . To compute the conditional expectation, $E_{t}$, we use Monte-Carlo integration consisting of $S=500$ simulations over a time horizon of $P=40$ for the public spending shock and 80 for the productivity shock. The simple algorithm we employ is as follows:

1. For an initial value of the exogenous state $x^{i}, x_{0}^{i}$, where $i=1,2$ refers to $g^{e}$ and $A$ respectively and the initial value refers to the steady-state, we draw $S$ replications of a vector of innovations for $x_{t}^{i}$, i.e. $\varepsilon^{i, s}=\left\{\varepsilon_{p}^{i}\right\}_{p=0}^{P}$.

2. Using the second-order solution to the model, we then compute $S$ realizations of $\mathbf{y}_{p}$, denoted $\mathbf{y}_{p}^{s}\left(x_{0}^{i}, \boldsymbol{\varepsilon}^{i, s}\right)$ for $p=0, \ldots, P$ and $s=1, \ldots, S$.

3. We repeat (2) using the same draws from (1) except we shock $\varepsilon_{0}^{i}$ by $\sigma^{i}$. The shocked realizations from the second-order solution are denoted $\mathbf{y}_{p}^{s}\left(x_{0}^{i}, \sigma_{i}, \varepsilon^{i, s}\right)$ for $p=0, \ldots, P$ and $s=1, \ldots, S$.

4. The second-order IRFs are then computed as

$$
\operatorname{IRF}\left(p, \sigma_{i}\right)=\frac{\mathbf{y}_{p}^{s}\left(x_{0}^{i}, \sigma_{i}, \boldsymbol{\varepsilon}^{i, s}\right)-\mathbf{y}_{p}^{r}\left(x_{0}^{i}, \boldsymbol{\varepsilon}^{i, s}\right)}{\mathbf{y}_{p}^{s}\left(x_{0}^{i}, \boldsymbol{\varepsilon}^{i, s}\right)}
$$

for $p=0, \ldots, P$.

5. The sample mean for the impulse responses is obtained by averaging across all $S$,

$$
\operatorname{IRF}^{S}\left(p, \sigma_{i}\right)=\frac{1}{S} \sum_{s=1}^{S} \operatorname{IRF}^{s}\left(p, \sigma_{i}\right)
$$

for each $p=0, \ldots, P$. 